\title{
Squalius recurvirostris Özuluğ \& Freyhof, 2011'in Dactylogyrid Parazit Faunası Üzerine Bir Araştırma
}

\author{
Mehmet Zeynel ELBAY (D) 1, Mehmet Oğuz ÖZTÜRK (D) 1* \\ ${ }^{1}$ Afyon Kocatepe Üniversitesi, Fen-Edebiyat Fakültesi, Afyonkarahisar \\ Geliş Tarihi (Received): 31.03.2021, Kabul Tarihi (Accepted): 27.06.2021 \\ $\square$ Sorumlu Yazar (Corresponding author*): oozturk@aku.edu.tr \\ (C) +902722281339 둉 +902722181935
}

öz

Bu çalışmanın amacı, Düzağaç-Akdeğirmen Baraj Gölü (Afyonkarahisar)'ndeki Squalius recurvirostris'in dactylogyrid parazit türlerini ve bu türlerin anatomik, morfolojik, metrik ve ekolojik özelliklerini tanımlamaktır. Araştırma metodolojisi kapsamında, Squalius recurvirostris örneklerinin deri yüzeyi, yüzgeç ve solungaçları dactylogyrid parazitler bakımından incelendi. Dactylogyrus sp. örneklerinin bazıları etil alkol ortamında muhafaza edilirken bazıları anatomik, morfolojik ve metrik özelliklerinin tanımlanması için daimi preparat yapıldı. Dactylogyrus naviculoides'in enfestasyon yüzdesi \%89,4 ve ortalama parazit yoğunluğu 27,1 124,1 dir. Dactylogyrus vistulae için bu değerler sırasıyla \%63,6 ve 4,5 $\pm 2,3$ dir. Her iki parazit türü tüm mevsimlerde kaydedildi. Dactylogyrus naviculoides'in yoğunluğu kış döneminde, Dactylogyrus vistulae'nin yoğunluğu ilkbaharda daha baskındı. Balık numuneleri yaş büyüklüğüne göre 5 gruba ayrıldı. Büyük yaş grubundaki balıklarda her iki Dactylogyrus türünün daha yüksek enfestasyona neden olduğu tespit edildi. Diğer yandan, her iki parazit türüne ait enfestasyon değerleri erkek balık bireylerinde dişilere göre daha yüksek değerde kaydedildi: Dactylogyrus naviculoides (\%89,4, 27,1 $\pm 24,1)$, Dactylogyrus vistulae $(\% 63,6,4,5 \pm 2,3)$. Sonuç olarak, Düzağaç-Akdeğirmen Baraj Gölü'ndeki Squalius recurvirostris'te 2 dactylogyrid parazit türü belirlenmiştir. Bu parazit türler, Squalius recurvirostris için yeni kayıttır. Böylece ilgili parazit türlerin coğrafik yayılışlarına yeni bir lokalite ve yeni bir konak ilave edilmiştir. Ayrıca, parazit türlerin enfestasyon olguları ekolojik yönden de değerlendirilmiştir.

Anahtar Kelimeler: Dactylogyrus naviculoides, Dactylogyrus vistulae, Squalius recurvirostris

\section{An Investigation on Dactylogyrid Parasite Fauna of Squalius recurvirostris Özuluğ \& Freyhof, 2011}

\begin{abstract}
The purpose of this study is to define the dactylogyrid parasite species of Squalius recurvirostris from DüzağaçAkdeğirmen Dam Lake (Afyonkarahisar) and their anatomical, morphological, metric and ecological characteristics. Within the scope of the research methodology, the skin surface, fins and gills of Squalius recurvirostris samples were examined for dactylogyrid parasites. While some of the Dactylogyrus sp. samples were kept in ethyl alcohol environment, some permanent preparations were made to define their anatomical, morphological and metric properties. The overall infection percentage of Dactylogyrus naviculoides belonging to the study findings was $89.4 \%$ and the average parasite density was $27.1 \pm 24.1$. For Dactylogyrus vistulae, these values are $63.6 \%$ and $4.5 \pm 2.3 \%$, respectively. Both types of parasites have been recorded in all seasons. The density of Dactylogyrus naviculoides was more dominant in the winter period and the density of Dactylogyrus vistulae in the spring compared to the other seasons. Fish samples were divided into 5 groups according to age. It was determined that both Dactylogyrus species caused higher infections in fish in the older age group. On the other hand, infection values of both parasite species were higher in male fish individuals compared to females: Dactylogyrus naviculoides (89.4\%, 27.1 \pm 24.1$)$, Dactylogyrus vistulae $(63.6 \%, 4.5 \pm 2.3)$. As a result, 2 dactylogyrid parasite species were identified in Squalius recurvirostris in Düzağaç-
\end{abstract}


Akdeğirmen Dam Lake. The parasitic species is the new record for Squalius recurvirostris. Thus, a new locality and a new host have been added to the geographical distribution of the related parasitic species. In addition, the cases of infection of parasitic species were evaluated ecologically.

\section{Keywords: Dactylogyrus naviculoides, Dactylogyrus vistulae, Squalius recurvirostris}

\section{GíRiş}

Yaklaşık 45 tür ile Squalius cinsi batı Palearktik bölgede geniş bir grubu temsil etmektedir. Özuluğ ve Freyhof, 2011 tarafından, Squalius cinsinin AvrupaAsya soyunun İç ve Batı Anadolu'daki temsilcilerinin yeniden incelenmesi sonucu 4 yeni tür tanımlanmıştır. Bu türlerden Squalius recurvirostris Özuluğ ve Freyhof, 2011 Eber, Akşehir ve Ilgın Gölü havzalarından tespit edilmiştir. S. recurvirostris'in biyolojik gelişimi, üreme verimliliği ile metabolik aktivitelerini tehdit eden parazit organizmalarının belirlenmesi, söz konusu balık türünün biyo-ekolojik özelliklerinin açığa çıkarılması bakımından önem taşımaktadır.

$\mathrm{Bu}$ çalışmanın amacı, Düzağaç-Akdeğirmen Baraj Gölü'nün kommunite üyelerinden Squalius recurvirostris'in dactylogyrid parazit fauna elemanlarının anatomik, morfolojik ve metrik özelliklerini ayrıntılı olarak tanımlamaktır. Ayrıca, söz konusu parazitlere ait enfestasyon olgularının konak balık boy ve eşey grupları ile mevsimler temelindeki değişimlerinin tanımlanması hedeflenmiştir. Elde edilecek verilerle, Türkiye dactylogyrid parazit faunasının oluşturulması çalışmalarına ve Düzağaç-Akdeğirmen Baraj Gölü’nün biyoekolojik özelliklerinin belirlenmesi çalışmalarına katkı sağlanacaktır.

\section{MATERYAL VE YÖNTEM}

\section{Araştırma alanı}

Düzağaç-Akdeğirmen Baraj Gölü, Afyonkarahisar ili Sincanlı İlçe sınırları içerisindeki Düzağaç Kasabasının 2 km kuzey doğusunda yer almaktadır. Baraj Gölü $38^{\circ} 48^{\prime}$ kuzey enlemi ile $30^{\circ} 15^{\prime}$ doğu boylamı koodinatlarında yer almaktadır. Baraj Gölü'nün maksimum işletme kotu $1130 \mathrm{~m}$, minumun işletme su kotu $1111 \mathrm{~m}$ ve aktif depolama hacmi $47367 \mathrm{hm}^{3}$ tür (Anonim, 2009).

\section{Materyal temini}

Çalışma konusu kapsamında incelenen Squalius recurvirostris örnekleri, Şubat 2012 ile Mart 2013 tarihleri arasında Akdeğirmen Baraj Gölü’nden fanyalı ağlarla yakalandı (Şekil 1). Numuneler, içinde ortam suyu bulunan plastik bidonlara aktarılıp, araştırma laboratuarına canlı olarak taşındı.

\section{Parazitolojik bakı}

Araştırma materyali olan Squalius recurvirostris örnekleri Balık ve ark. (2004)'e göre yaş gruplarına ayrıldı. Laboratuvarda 24 ila 48 saat içinde incelenen balıklar bu süre zarfında havalandırmalı akvaryum tanklarında muhafaza edildi. Çalşma kapsamında, balıkların deri yüzeyinde $x 10$ büyütmeli büyüteç yardımıyla ön parazitolojik bakı yapıldı. Bunu takiben yüzgeç ve solungaçlar dissekte edilerek içinde fizyolojik su bulunan petri kaplarına alındı. Bu materyaller, ışık kaynağı ile desteklenmiş stereo mikroskop yardımıyla incelendi. Parazite rastlanması halinde disseksiyon iğnesi, pipet ve fırça yardımıyla fizyolojik su ortamına alındı. Parazitlerin bulundukları yer ve sayılar her balık için ayrı not edildi.

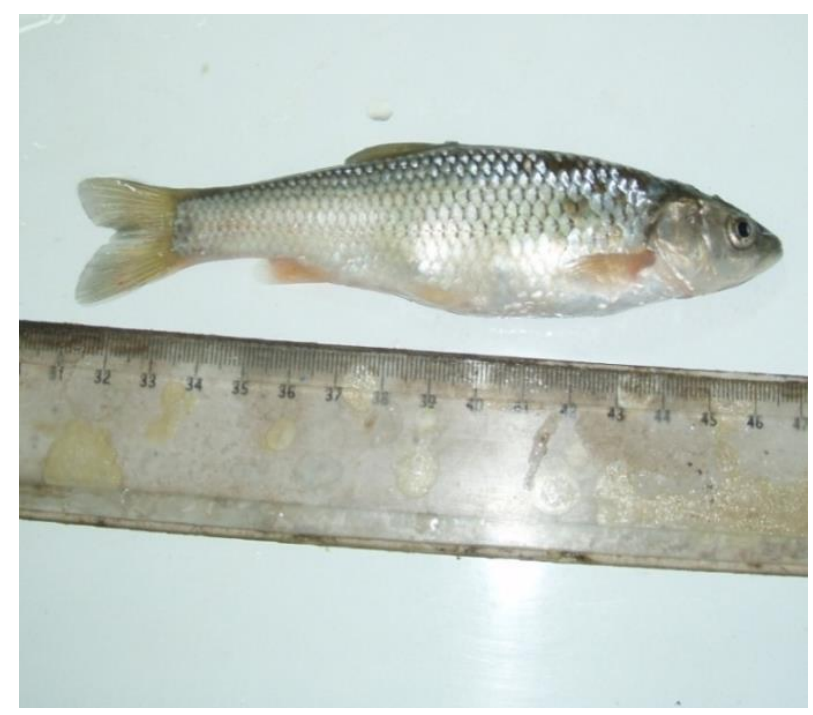

Şekil 1. Squalius recurvirostris Özuluğ \& Freyhof, 2011

\section{Parazitolojik preparasyon ve değerlendirme}

Balıkların solungaçlarında kaydedilen Dactylogyrus örneklerinin bir kısmı \%70'lik etil alkol ortamında depolandı. Diğer bir kısmı ise gliserol-jelâtin ortamı kullanılarak daimi preparat haline getirildi ve iki parazit türün 
anatomik-morfolojik ve metrik özelliklerinin tanımlanmasında yararlanıldı. Parazitlerin tür tanımlamasında Bychovskaja ve ark. (1962)'dan yararlanıldı. Fotoğraflar Olympus $\mathrm{CH} 20$ ışık mikroskobunda çekildi. Parazitolojik bulguların değerlendirilmesinde SPSS 11.5 programından yararlanıldı. Enfestasyon verileri mevsimler, balık boy grupları ve konak balık eşey farklılığına göre Ki-Kare ve Anova testleri kullanılarak değerlendirildi.

\section{BULGULAR VE TARTIŞMA}

Çalışma süresince 66 balık örneği incelenmiştir. Bu örneklerin 33'ü dişi 33'ü erkektir. İncelenen örneklerin 5 farklı yaş sınıfına ait olduğu tespit edilmiştir. DüzağaçAkdeğirmen Baraj Gölü'nden temin edilen S. recurvirostris türünün solungaçlarında Dactylogyrus naviculoides ve Dactylogyrus vistulae olmak üzere iki dactylogyrid parazit türü bulunmuştur. Her iki türün anatomik, morfolojik ve metrik özellikleri ile konak balık üzerindeki enfestasyon değerleri detaylı olarak tanımlanmıştır.

\section{Dactylogyrus naviculoides}

Vücut uzunluğu 510-550 (530) $\mu \mathrm{m}$, ovaryum seviyesindeki maksimum genişliği 100-120 (115) $\mu$ m olarak ölçüldü. Vücudun anteriör subterminalinde küremsi şekilli farinks 27-29 (28) x 27-29 (28) $\mu \mathrm{m}$ boyutlarında belirlendi (Şekil 2).

Vücudun anteriör subterminalinde yer alan kitinsi yapıdaki kopulatör organ, konik şekilli kaide kısmı ile yarı çember şeklinde kıvrılan bir tüpsü yapıdan meydana gelmiştir (Şekil 3). Destekleyici yapının distal kısmı yassı-konkav şekilli ve serbest iken proksimal kısmı silindirik düz çubuk şeklinde kopulasyon tüpüne bağlanmaktadır. Kopulatör organının total boyu 38-40 (38) $\mu \mathrm{m}$ ölçüldü.

Kitinoit yapılı vajinal tüp, kopulatör organının posteriör lateralinde yer almaktadır. Vaginal tüpün boyu 75-76 (75) $\mu \mathrm{m}$, eni $2 \mu \mathrm{m}$ ölçüldü. Vajinal tüpün kaide kısmı huni şeklinde, orta bölümü kendi etrafında kıvrılma göstermiş tüpsü yapı şeklinde ve uç kısmı küçük papiller taşıyan konik şeklinde görüntülendi (Şekil 3).

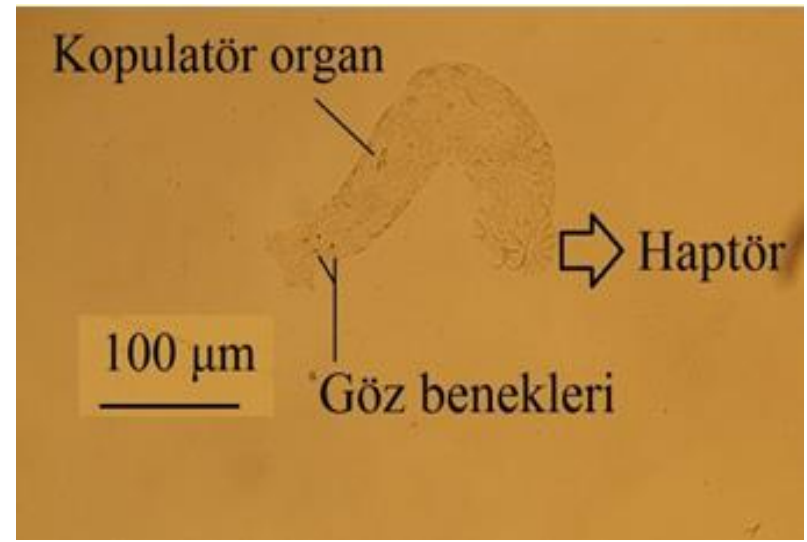

Şekil 2. Dactylogyrus naviculoides'de genel görünüm

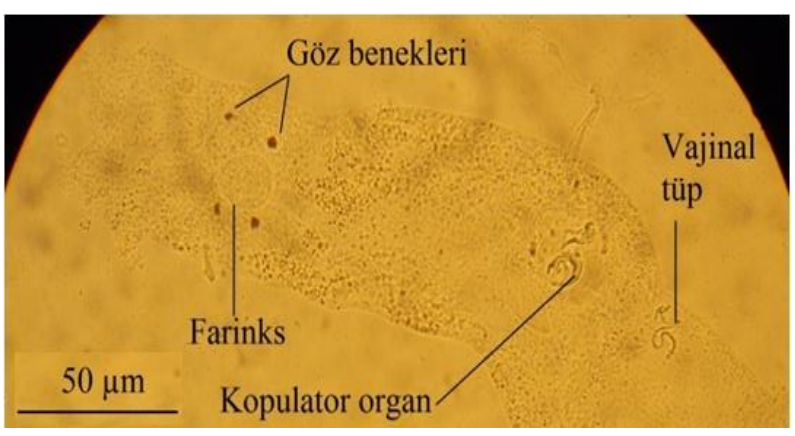

Şekil 3. Dactylogyrus naviculoides'de anteriör kısım

Dactylogyrus naviculoides'in posteröründe yer alan ovalimsi haptörün (tutkaç) boyu 87-94 (90) $\mu \mathrm{m}$, eni 112-120 (115) um kaydedildi. Haptörün median alanındaki median kancanın dorsal kök boyu 7-8 (7) $\mu \mathrm{m}$, ventral kök boyu 15-16 (15) $\mu \mathrm{m}$, kancanın total boyu 40-42 (40) $\mu \mathrm{m}$, kanca gövde boyu 32-33 (32) $\mu \mathrm{m}$ ve distal uç kısım boyu 9-10 (9) $\mu \mathrm{m}$ olarak ölçüldü. Median kancalar arasındaki dorsal çubuğun orta kısmı yay şeklinde çukur iken uç kısımları oval küt yapılı sonlanmaktadır (Şekil 4). Dorsal çubuğun boyu 3-4 $\mu \mathrm{m}$, genişliği 27-28 (27) $\mu \mathrm{m}$ kaydedildi. Ters T şeklindeki ventral çubuğun gövdesi iki kola ayrılmıştır (Şekil4,5). Ventral çubuğun gövde boyu 7-8 $\mu \mathrm{m}$, iki kol arasındaki genişliği 22-23 (22) um olarak ölçüldü. Haptörün kenarında sıralanan yan kancaların tamamı şekil ve büyüklük bakımından birbirine benzerdir. Yan kanca kök boyu 12-13 (12) $\mu \mathrm{m}$, gövde boyu 8-9 (9) ve geniş hilâl şeklindeki kancanın 6-7 (6) $\mu \mathrm{m}$ boyunda olduğu kaydedildi (Şekil 5). 


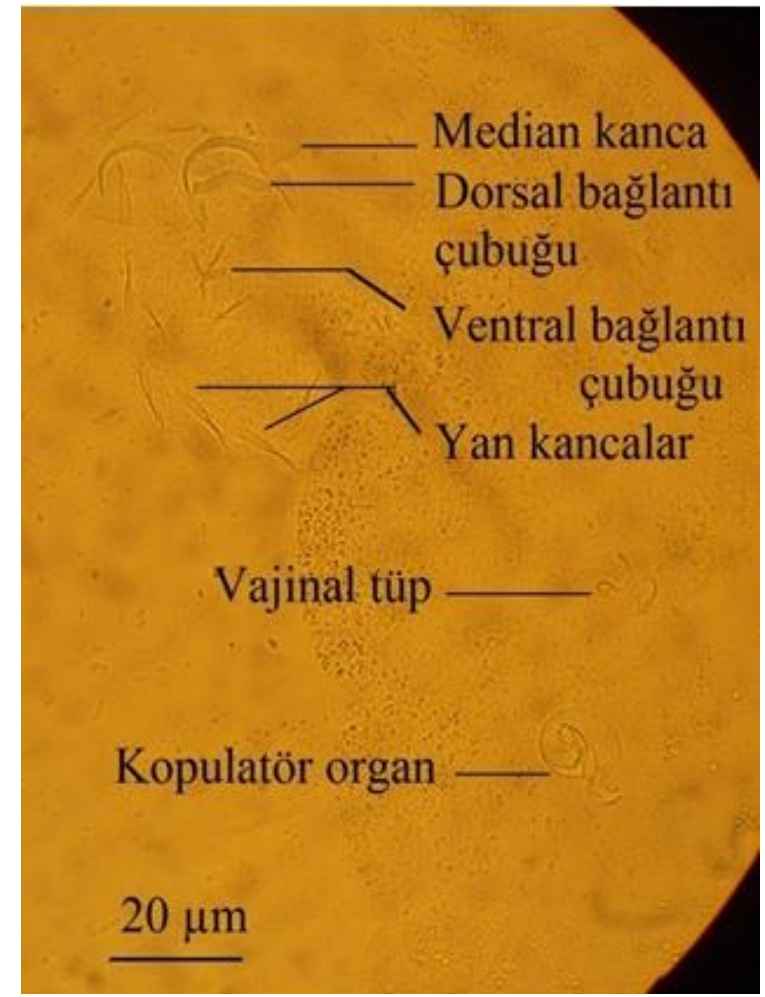

Şekil 4. Dactylogyrus naviculoides'in kitinsi yapıdaki organları

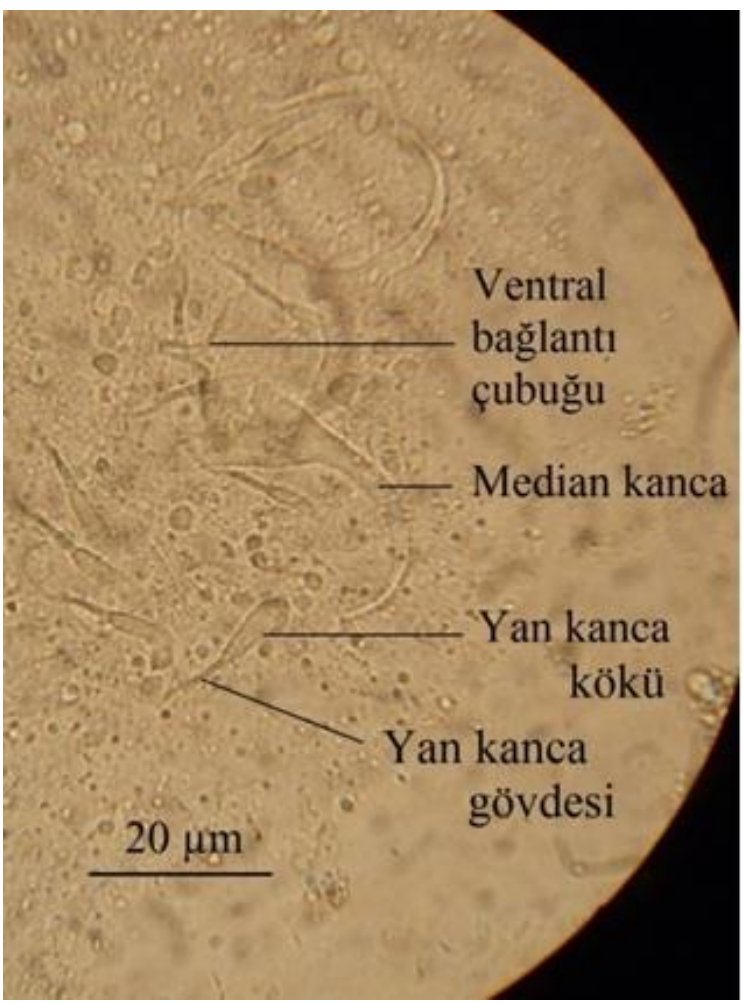

Şekil 5. Dactylogyrus naviculoides'in haptör kısmında yer alan kitinsi tutunma elemanları

\section{Dactylogyrus vistulae}

Büyük monogen trematodlardan olan Dactylogyrus vistulae'nin vücut uzunluğu 1260-1760 (1580) $\mu \mathrm{m}$, ovaryum seviyesindeki maksimum genişliği 155-220 (210) $\mu \mathrm{m}$ olarak ölçüldü. Vücudun anteriöründe subterminal konumlu olarak yer alan farinks, 60-72 (70) $\mu \mathrm{m}$ boyunda ve 60-72 (70) $\mu \mathrm{m}$ eninde kaydedildi. Farinksi takip eden kısa ösafagustan sonra, transversal çatallanma göstermeyen düz çekum şeklindeki iki bağırsak kolu lateral alanlardan ilerleyerek tutkaç seviyesine kadar uzanmakta ve burada birleşerek sonlanmaktadır.

Anteriör subterminalde, median alanda yer alan kitinsi yapıdaki kopulatör organ 67-72 (70) $\mu \mathrm{m}$ uzunluğunda belirlendi. Tenis raketi şeklindeki vajinal tüpün distal tarafı levha şeklinde yassılaşmıştır. Vajinal tüpün total boyu 42-43 (42) x 6-7 (7) ㅆm boyutlarında ölçüldü.

Vücudun posterior terminalinde yer alan haptörün boyu 110-120 (116) $\mu \mathrm{m}$, eni ise 125-150 (130) $\mu \mathrm{m}$ olarak ölçüldü. Haptörde kitin yapılı 14 yan kanca ile 2 median kanca yer almaktadır. Median kancanın dorsal kök uzantısı 10-11 (11) $\mu \mathrm{m}$, ventral kök uzantısı 41-42 (41) $\mu \mathrm{m}$, kanca total boyu 58-59 (59) $\mu \mathrm{m}$, ana gövde kısım boyu 23-23 (23) um ve kanca uç kısmı 12-13 (12) $\mu \mathrm{m}$ olarak ölçüldü. Median kancaları birbirine bağlayan dorsal bağlayıcı çubuğun uç kısımları oval şekilli, orta kısmı ise geniş bir yayı andırmaktadır. Bu çubuğun boyu 22-23 (22) $\mu \mathrm{m}$, eni 5-4 (4) $\mu \mathrm{m}$ olarak belirlendi. Tutkacın kenar kısımlarında yer alan yan kancalardan yedinci çift oldukça iyi gelişmiş olup, boy uzunluğu 42-43 (42) $\mu \mathrm{m}$ olarak ölçüldü. Şekil ve boyca birbirlerine eşit olan diğer yan kanca çiftleri 23-24 (24) $\mu \mathrm{m}$ olarak kaydedildi.

\section{Genel Parazitik Enfestasyon Bulguları}

Konak üzerindeki enfestasyon yaygınlığı en yüksek tür $\% 89,4$ ile $D$. naviculoides'tir. $D$. vistulae'nin enfestasyon oranı ise $\% 63,6$ 'dır. D. naviculoides diğer parazitolik enfestasyon değerleri bakımından daha baskındır (Tablo 1).

\section{Mevsimler Temelinde Parazitik Enfestasyon Bul- guları}

Enfestasyon verileri, ilkbahar, yaz, sonbahar ve kış dönemlerine göre değelendirildi (Tablo 2). D. naviculoides türüne ait maksimum ve ortalama parazit sayısında en yüksek seviye kış mevsiminde, en düşük değer ise sonbahar döneminde kaydedilmiştir. Diğer mevsimlerdeki enfestasyon değerleri ise birbirine ya- 
kındır. D. vistulae tüm mevsimlerde enfestasyon olgusu gösteren bir tür olup, enfestasyon yaygınlığı kış ve ilkbahar döneminde en yüksek değerdedir.

Tablo 1. Düzağaç-Akdeğirmen Baraj Gölü’ndeki Squalius recurvirostris'te bulunan parazit türlere ait genel enfestasyon değerleri

\begin{tabular}{|c|c|c|}
\hline Parazit türler & $\mathrm{N},(\%)$ & M-M ve X $\pm S . D$. \\
\hline Dactylogyrus naviculoides & $59(89,4)$ & $3-130(27,1 \pm 24,1)$ \\
\hline Dactylogyrus vistulae & $42(63,6)$ & $1-26(4,5 \pm 2,3)$ \\
\hline
\end{tabular}

Tablo 2. Parazit türlere ait enfestasyon değerlerinin mevsimlere göre dağılımı

\begin{tabular}{|c|c|c|c|c|}
\hline \multirow[t]{2}{*}{ Mevsimler } & \multirow[t]{2}{*}{$\begin{array}{l}\text { İncelenen } \\
\text { Balık Sayısı }\end{array}$} & \multirow{2}{*}{$\begin{array}{l}\text { Enfestasyon } \\
\text { Verileri } \\
\mathrm{N},(\%)\end{array}$} & \multicolumn{2}{|c|}{ D. naviculoides $D$. vistulae } \\
\hline & & & $17(89,5)$ & $14(73,7)$ \\
\hline İlkbahar & 19 & $\begin{array}{l}\text { X } \pm \text { S.D. } \\
\text { M-M }\end{array}$ & $\begin{array}{l}23,4 \pm 17,9 \\
6-80\end{array}$ & $\begin{array}{l}43,7 \pm 34,5 \\
2-126\end{array}$ \\
\hline \multirow[b]{2}{*}{ Yaz } & & $\mathrm{N},(\%)$ & $21(91,3)$ & $13(56,5)$ \\
\hline & 23 & $\begin{array}{l}\text { X } \pm \text { S.D. } \\
\text { M-M }\end{array}$ & $\begin{array}{l}24,9 \pm 21,1 \\
4-96\end{array}$ & $\begin{array}{l}21,6 \pm 12,1 \\
2-80\end{array}$ \\
\hline \multirow{3}{*}{ Sonbahar } & \multirow{3}{*}{13} & $\mathrm{~N},(\%)$ & $12(92,3)$ & $7(53,8)$ \\
\hline & & X \pm S.D. & $10,9 \pm 3,9$ & $5,7 \pm 4,1$ \\
\hline & & M-M & $6-18$ & $1-16$ \\
\hline \multirow[b]{2}{*}{ Kış } & \multirow[b]{2}{*}{11} & $\mathrm{~N},(\%)$ & $9(81,8)$ & $8(72,7)$ \\
\hline & & $\begin{array}{l}X \pm S . D . \\
M-M\end{array}$ & $\begin{array}{l}48,2 \pm 47,6 \\
3-130\end{array}$ & $\begin{array}{l}9,0 \pm 4,3 \\
3-16\end{array}$ \\
\hline
\end{tabular}

Konak Balık Yaş Grupları Temelinde Parazitik Enfestasyon Bulguları

Araştırma sürecinde incelenen Squalius recurvirostris örnekleri 5 yaş grubuna ayrıldı (Tablo 3 ). Konak balığın tüm yaş gruplarında en yaygın bulunan tür $D$. naviculoides olup, enfestasyon yaygınlığı 2, 4 ve 5 yaş gruplarında \%100 olarak kaydedildi. Bir balıkta kaydedilen maksimum $D$. naviculoides sayısı ise 116 adet ile 3 yaş grubunda, en düşük enfestasyon olgusu ise en küçük boy grubundaki balıklarda görüldü. Dactylogyrus vistulae türüne ait en düşük enfestasyon yaygınlığı III yaş grubu balıklarda ve en yüksek değer ise $V$ yaş grubu balıklarda kaydedilmiştir. Benzer şekilde bir balıkta kaydedilen maksimum Dactylogyrus vistulae sayısı ve ortalama parazit yoğunluğuna ait en yüksek değer $V$ yaş grubu balıklarda tanımlanmıştır.

Tablo 3. Squalius recurvirostris'un yaş gruplarına göre parazit türlere ait enfestasyon değerlerinin dağılımı

\begin{tabular}{cclcc}
\hline $\begin{array}{c}\text { Balık Yaş } \\
\text { Grupları }\end{array}$ & $\begin{array}{l}\text { Incelenen } \\
\text { Balık Sayısı }\end{array}$ & $\begin{array}{l}\text { Enfestasyon Ver- } \\
\text { ileri }\end{array}$ & D. naviculoides & D. vistulae \\
\hline \multirow{2}{*}{ I } & \multirow{2}{*}{25} & N, (\%) & $20(80,0)$ & $15(60,0)$ \\
& & X \pm S.D. & $11,2 \pm 5,7$ & $8,1 \pm 7,2$ \\
& & M-M & $4-24$ & $1-32$ \\
\hline \multirow{2}{*}{ II } & \multirow{2}{*}{13} & N, (\%) & $13(100)$ & $8(61,5)$ \\
& & X \pm S.D. & $11,4 \pm 2,1$ & $6,1 \pm 4,8$
\end{tabular}


Squalius recurvirostris Özuluğ \& Freyhof, 2011'in Dactylogyrid Parazit Faunası Üzerine Bir Araştırma

\begin{tabular}{cclll}
\hline & & M-M & $3-46$ & $2-16$ \\
\hline \multirow{3}{*}{ III } & & N, (\%) & $10(83,3)$ & $7(58,3)$ \\
& \multirow{2}{*}{12} & X \pm S.D. & $38,5 \pm 34,9$ & $15,7 \pm 12,4$ \\
& & M-M & $6-116$ & $2-46$ \\
\hline \multirow{3}{*}{ IV } & & N, (\%) & $11(100)$ & $8(72,7)$ \\
& \multirow{2}{*}{11} & X \pm S.D. & $43,8 \pm 35,1$ & $22,5 \pm 22,1$ \\
& & M-M & $20-130$ & $4-64$ \\
\hline \multirow{3}{*}{ V } & & N, (\%) & $5(100)$ & $4(80,0)$ \\
& \multirow{2}{*}{5} & X \pm S.D. & $34,0 \pm 5,9$ & $56,3 \pm 2,1$ \\
& & M-M & $8-96$ & $4-126$ \\
\hline
\end{tabular}

Tablo 4. Squalius recurvirostris'in eşey gruplarına göre, parazit türlere ait enfestasyon değerlerinin dağılımı

\begin{tabular}{lllll}
\hline $\begin{array}{l}\text { Balık Eşey } \\
\text { Grupları }\end{array}$ & $\begin{array}{l}\text { İncelenen BalıkEnfestasyon } \\
\text { Sayısı }\end{array}$ & Verileri & D. naviculoides & D. vistulae \\
\hline \multirow{3}{*}{ Dişi } & & N, (\%) & $31(93,9)$ & $20(60,6)$ \\
& \multirow{2}{*}{33} & X \pm S.D. & $32,4 \pm 28,6$ & $39,5 \pm 29,1$ \\
& & M-M & $6-130$ & $1-126$ \\
Erkek & \multirow{3}{*}{33} & N, (\%) & $28(84,8)$ & $22(66,6)$ \\
& & X \pm S.D. & $19,3 \pm 18,7$ & $7,5 \pm 7,3$ \\
& & M-M & $3-68$ & $2-32$ \\
\hline
\end{tabular}

Konak Balık Eşey Grupları Temelinde Parazitik Enfestasyon Bulguları

Squalius recurvirostris örnekleri erkek ve dişi olmak üzere iki eşey grubuna ayrıldı. Parazit türlere ait enfestasyon değerlerinin konak balık eşey gruplarına göre dağılımı Tablo 4'te verilmiştir. Elde edilen bulgulara göre, Dactylogyrus vistulae 'nin enfestasyon yaygınlığı hariç, her iki dactylogyrid parazit türüne ait tüm enfestasyon değerlerinin dişi $S$. recurvirostris bireylerinde erkeklere göre daha yüksek olduğu kaydedilmiştir.

\section{Genel Taksonomik Değerlendirme}

Tanımlanan 2 metazoon parazitin tür vücutlarının dorsoventral yönde yassılaşmış ve bilateral simetrili olmaları nedeniyle yassısolucanlar olarak bilinen Platyhelminthes taksonuna aittir. Söz konusu parazit türler, halkasız vücut yapıları ve vücutlarının posteriorunde kitinsi kancalarla donanmış tutkaç bulundurmalarıyla Monogenea altsınıfının Dactylogyrus genusunda yer almaktadırlar (Bychowskajave ark.,1962).

D.naviculoides'in haptör kısmında ters "T" şeklindeki ventral bağlantı çubuğunun posteriörden anteriörüne doğru bir yarığın olması, kopulatör organın konik şekilli kaide kısmı ile yarı çember şeklinde kıvrılan bir tüpsü yapıdan meydana gelmesi, vajinal tüpün kaide kısmının huni şeklinde, orta bölümünün kendi etrafında kıvrılma gösteren tüpsü yapı şekli ve uç kısmının küçük papilsi uzantıları olan koni şeklinde olmasıyla diğer türlerden ayrılmıştır (Bychovskaja ve ark.,1962). İkinci tür D. vistulae, vajinal tüpünün raket şeklinde olması ve kopulatör organdaki destek tüpün uç kısmının çatalsı olmasıyla diğer türlerden ayrılmaktadır (Bychovskaja ve ark.,1962). D.vistulae türünün anatomik, morfolojik ve metrik özellikleri Yazmen ve Öztürk (2014) tarafından görsel şekiller desteğinde detaylı olarak tanımlandığı için, mevcut bu çalışmada ilgili türe ait şekillere yer verilmemiştir.

\section{Genel Parazitolojik Değerlendirme}

Araştırma kapsamında incelenen Squalius recurvirostris Özuluğ ve Freyhof, 2011 tarafından tanımlanan yeni bir tür olup, üzerinde günümüze kadar herhangi bir parazitolojik çalışma yapılmamıştır. Dolayısıyla araştırma kapsamında bulunan her iki parazit tür, Squalius recurvirostris'in parazit faunası için yeni kayıttır.

Squalius genusu içindeki diğer balık türleri üzerinde çeşitli parazitolojik araştırmalar bulunmaktadır (Moravec ve Scholz, 1991; Sterud ve Appleby, 1997; İnnal ve Keskin, 2006; İnnal ve ark., 2007; Koç ve ark., 2006; Galli ve ark., 2001; Tieri ve ark., 2006; Dzika ve ark., 2007; Stonajovski ve ark., 2010). Ayrıca, bu çalışmada tanımlanan parazit türlerden Dactylogyrus vistulae, daha önce Leuciscus cephalus'ta (Loot ve ark., 2007; Kurupınar ve Öztürk, 2009; Djikanovic ve ark., 2011; Açıkel ve Öztürk, 
2012; Yazmen ve Öztürk, 2014); D. naviculoides ise Chondrostoma regium'da tanımlanmıştır (Turgut Neary ve ark., 2012). Araştırma sürecinde elde edilen parazitolojik verilerle, diğer araştırıcıların çalışma sonuçları karşılaştırıldığında, benzer bulguların yanı sıra farklı sonuçlara da rastlanmıştır. Poulin (2007) benzer habitatlarda yaşayan konak balıkların parazit fauna benzerliklerini konak-parazit özgüllüğü ile açıklarken, farklı konakların parazit tür farkıııklarını habitatların ekolojik çeşitliliğinin bir yansıması olarak tanımlamaktadır.

\section{Mevsimler Temelinde Parazitolojik Değerlendirme}

Dactylogyrus vistulae'nin konak balıktaki mevsimsel değişimini inceleyen Kurupınar and Öztürk (2009), en yüksek enfestasyon olgusunu ilkbahar döneminde belirlemiştir. Stonajovski ve ark. (2010), Leuciscus cephalus'un solungaçlarında tespit ettiği $D$. vistulae populasyonunun sonbahar ve yaz döneminde tamamen kaybolduğunu, buna karşın su sıcaklığının düşük olduğu ilkbahar-kış dönemlerinde baskın bir populasyon özelliği gösterdiğini kaydetmiştir. Leuciscus cephalus'un solungaç lamellerinde $D$. vistulae türünü bulan Açıkel ve Öztürk (2012), benzer ekolojik bulgulara işaret etmektedir. Yazmen ve Öztürk (2014) Dactylogyrus vistulae türünü tüm mevsimlerde kaydetmiştir. Turgut-Neary ve ark. (2012) $D$. naviculoides and $D$. vistulae türlerinin $L$. cephalus daki enfestasyon olgusunu ilkbahardan yaz dönemine artış, sonbahara doğru azalma gösterdiğini tespit etmiştir. Mevcut bu çalışma süresince de elde edilen bulgulara göre ise, $D$. naviculoides ve $D$. vistulae için konak balıktaki en baskın enfestasyon döneminin ilkbahar daha sonrada kış dönemidir. Khan ve Thulin (1991), konak balıklardaki ektoparaziter enfensiyon olgularının mevsimlere göre değişimini şu şekilde açıklamaktadır: Bu canlılar çevre etkenleri ile doğrudan temas halinde olan balığın deri, solungaç ve yüzgeç gibi organları üzerinde yaşamaktadırlar. Bu nedenle dactylogyrid parazit canlılar, ortamdaki sıcaklık vb. abiyotik etkenlerdeki değişimlere doğrudan maruz kalmakta ve sonuçta enfestasyon olguları da değişkenkenlik göstermektedir.

\section{Konak Balık Yaş Grupları Temelinde Parazitolojik Değerlendirme}

Parazit canlıların neden olduğu enfestasyonun şiddeti ile üzerinde yaşadıkları konak canlıların yaş veya boy grupları arasında bağlantı olduğu ifade edilmiştir (Tieri ve ark., 2006). Açıkel ve Öztürk (2012), L.cephalus'un her yaş grubunda tespit ettiği Dactylogyrus vistulae türüne ait en yüksek enfestasyon olgusunu, 2 ve 3 yaş grubundaki balıklarda belirlemiştir. Buna karşın, Yazmen ve Öztürk (2014) aynı parazit türüne ait en yüksek enfes- tasyonu, en büyük boy grubundaki L.cephalus'larda tespit etmiştir. Mevcut bu araştırma süresince kaydedilen iki Dactylogyrus türüne ait enfestasyon verileri, Yazmen ve Öztürk (2014)'ün verilerini destekler niteliktedir. Bu durum, genç balıkların bağışıklık sisteminin daha az gelişmiş olması ya da balıkların yaşa bağı olarak parazit canlılara daha fazla maruz kalmalarıyla açıklanmaktadır (Tieri ve ark., 2006).

\section{Konak Balık Eşey Grupları Temelinde Parazitolojik Değerlendirme}

Balıkların solungaç, deri ve yüzgeçlerinde parazit olarak yaşayan bazı Dactylogyrus türlerinin dişi L.cephalus'larda, erkek bireylere nazaran daha fazla parazitlenme gösterdiği belirlenmiştir (Kurupınar ve Öztürk, 2009; Açıkel ve Öztürk, 2012; Yazmen 2012). Bu çalışma sürecinde kaydedilen parzit türlere ait enfestasyon verileri de benzer niteliktedir.

Kennedy (1972), dişi balık bireylerinin erkeklere göre daha fazla paraziter enfestasyona sahip olduğuna işaret etmektedir. Bunun nedeni olarak ise; balığın cinsiyetine bağlı olarak tercih ettiği beslenme alışkanlığı, hormonal dengesi, aşırı stres altında olması, yumurta dökme sürecinde zamanın büyük kısmını zemin kısmında geçirmesi ve bu süre içinde bentik faunada yer alan canlılarla beslenmesi gibi faktörlerin etkili olduğunu belirtmektedir.

\section{SONUÇ}

Sonuç olarak bu çalışmada, günümüze kadar herhangi bir parazitolojik araştırma yapılmayan ve Türkiye balık faunası için yeni bir tür olan Düzağaç-Akdeğirmen Baraj Gölü'ndeki Squalius recurvirostris'te 2 dactylogyrid parazit türü belirlenmiş̧tir. Söz konusu parazit türler, Düzağaç-Akdeğirmen Baraj Gölü ve Squalius recurvirostris için yeni kayıttır. Böylece sözü edilen parazit türlerin yayılışlarına yeni bir lokalite ve yeni bir konak ilave edilmiştir. Ayrıca, her iki parazit türüne ait enfestasyon olgularının; mevsimler ile konak balığın yaş ve eşey grupları dikkate alınarak değerlendirilmesiyle, yerel habitat, konak ve parazit türler arasındaki ekolojik etkileşim özelliklerinin belirlenmesi çalışmalarına katkı sağlanmıştır.

\section{TEŞEKKÜR}

Bu çalışma Afyon Kocatepe Üniversitesi Bilimsel Araştırma Projeleri Birimi tarafından 13.Fen.Bil.01 nolu proje kapsamında desteklenmiştir.

\section{KAYNAKLAR}

Açıkel, M., Öztürk, O.M. (2012). Investigations on ectoparasitic helminth fauna of Squalius cephalus (L., 1758) linked to 
ecologic factors in Serban Dam Lake, Turkey. Fresenius Environmental Bulletin, 21(12): 3614-3617.

Anonim (2009). Düzağaç-Akdeğirmen Barajı ve sulaması tesis tanıtma föyü. DSI 183 Şube Müdürlüğü, Afyonkarahisar.

Balık, S., Sarı, H.M., Ustaoğlu, M.R., Illhan, A. (2004). Işıklı Gölü (Çivril, Denizli, Türkiye) Tatılısu Kefali (Leuciscus cephalus L., 1758) Populasyonunun Yaş ve Büyüme özellikleri. Ege University Journal of Fisheries \& Aquatic Sciences, 21(3-4): 257-262.

Bychovskaja-Pavlovskaja, I.E., Gusev, A.V., Dibinina, M.V., Izjumowa, N.A., Smirnova, T.S., Sokolovskaja, I.L., Štein, G.A., Šulman, S.S., Epstein, U.M. (1962). Key to parasites of freshwater fishes of the USSR. Publ. House of the USSR Acad. Sci. Moscow, Leningrad.

Djikanovic, V., Paunovic, M., Nikolic, V., Simonovic, P., Cakic, P. (2011). Parasito fauna of freshwater fishes in the Serbian open waters: a checklist of parasites of freshwater fishes in Serbian open waters. Rev Fish Biol Fisheries, 22: 297-324.

Dzika, E., Kusztala, A., Kusztala, M. (2007). Parasites of carp bream, Abramis brama, from Lake Jamno, Poland. Helminthologia, 44(4): 222-225.

Galli P., Stefani, F., Zaccara, S., Crosa, G. (2002). Occurrence of monogenea in Italian freshwater fish (Po River Basin). Parassitologia, 44: 189-197.

Innal, D., Keskin, N. (2006). The infection of european chub (Leuciscus cephalus L. 1758) with Ligula intestinalis plerocercoids in Çamkoru Lake (Turkey). Journal of Animal and Veterinary Advances, 5(2): 108-110.

İnnal, D., Keskin, N.,Erk'akan, F. (2007). Distribution of Ligula intestinalis (L.) in Turkey. Turkish Journal of Fisheries and Aquatic Sciencies, 7: 19-22.

Kennedy, C.R.(1972). Parasite communities of freshwater ecosystems. In: R.B.Clarke, R.J. Wooton (Eds.), Essays in Hydrobiology University of Exeter Press, Exeter, 53-68.

Khan, R.A., Thulin, J. (1991). Influence of pollution on parasites of aquatic animals. Adv Parasitol, 30: 201-238.

Koç, H.T., Erdoğan, Z., Coz-Rakovac, R. (2006). The occurrence of Ligula intestinalis (L.) observed in chub (Leuciscus cephalus L.) from Caparlipatlak Dam Lake, İvrindi-Balıkesir, Turkey. Periodicum Biologorum, 108(2): 183-187.

Kurupınar, E., Öztürk, M.O. (2009). Mevsimsel değişime ve boy büyüklüğüne bağlı olarak Leuciscus cephalus L.'un (Serban Baraj Gölü, Afyonkarahisar) helmint faunası. Türkiye Parazitoloji Dergisi, 33(3): 248-253.

Loot, G., Reyjol, Y., Poulet, N., Simkova, A., Blanchet, S., Lek, S. (2007). Effects of small weirs of fish parasite communities. Parasitol Res, 101: 1265-1276.

Moravec, F., Scholz, T. (1991). Occurence of endohelminths in chub, Leuciscus cephalus, of the Rokytná River, Czechslovakia, Aćta Soc. Zool. Bohemoslov, 55: 12-28.

Özuluğ, M.,Freyhof, J. (2011). Revision of the genus Squalius in Western and Central Anatolia, with description of four new species (Teleostei: Cyprinidae). Ichthyological Exploration of Freshwaters, 22(2): 107-148.

Poulin, R. (2007). The structure of parasite communities in fish hosts: ecology meets geography and climate. Parassitologia, 49: 169-172.

Sterud, E., Appleby, C. (1997). Parasites of dace (L. leuciscus), ide (L. idus) and chub (L. cephalus) from south-eastern Norway. Bull Scand Soc. Parasitol, 7(2): 19-24.

Stojanovski, S., Hristovski, N., Cakic, P., Hristovski,M., Velkova-Jordanoska, L.,Blazekovic, D. (2010). Monogenean trematods of chub Leuciscus cephalus albus Bonaparte, 1838 from the Lake Ohrid (Macedonia). Second balkan conference on biology special edition/on-line 21-23 May 2010, Plovdiv, Macedonia.

Tieri, E., Mariniello, L., Ortis, M., Berti, M., Battistini, M.L. (2006). Endoparasites of chub (Leuciscus cephalus) in two rivers of the Abruzzo region of Italy. Veterinaria Italiana, 42(3): 271-279.

Turgut-Neary, E., Develi, N., Özgül, G. (2012). Occurrence of Dactylogyrus species (Platyhelminths, Monogenean) on Cyprinids in Almus Dam Lake, Turkey. Turkish Journal of Fisheries and Aquatic Sciences, 12: 15-21.

Yazmen, H., Öztürk, M.O. (2014). Research studies on Anatomical, Morphological and Parasitic Characteristics of Dactylogyrus vistulae (Platyhelminthes). Journal of Academic Documents for Fisheries and Aquaculture, 1: 17-22. 